Research, Society and Development, v. 9, n. 10, e6529109100, 2020

(CC BY 4.0) | ISSN 2525-3409 | DOI: http://dx.doi.org/10.33448/rsd-v9i10.9100

Postos de revenda de combustíveis em Belém-PA: o licenciamento ambiental e os riscos à contaminação do solo e da água subterrânea

\title{
Gas stations in Belém-PA: the environmental licensing and the risks of soil and groundwater contamination
}

Estaciones de servicio en Belém-PA: licencias ambientales y riesgo a la contaminación del suelo y las aguas subterráneas

Recebido: 06/10/2020 | Revisado: 09/10/2020 | Aceito: 11/10/2020 | Publicado: 12/10/2020

Cleyanne Kelly Barbosa Souto

ORCID: https://orcid.org/0000-0003-1036-2016

Universidade Federal do Pará, Brasil

E-mail: cleyannes@gmail.com

Giovanni Chaves Penner

ORCID: https://orcid.org/0000-0003-0335-5352

Universidade Federal do Pará, Brasil

E-mail: penner@ufpa.br

\section{Resumo}

Atividades poluidoras precisam passar pelo processo de licenciamento ambiental como garantia do seu funcionamento ambientalmente adequado. $\mathrm{O}$ presente trabalho analisou $\mathrm{o}$ cadastro de licenças do segmento postos de revenda de combustíveis referente ao município de Belém-PA e relacionou com o adensamento urbano e com as cargas muito superficiais do aquífero livre, fatores estes que podem comprometer a qualidade ambiental e trazer riscos à saúde pública. Para tanto efetuou-se pesquisa bibliográfica, bem como levantamento de informações em bancos de dados da secretaria municipal, estadual, cadastro federal e corpo de bombeiros. Ademais, conclui-se que o quantitativo de postos de revenda de combustíveis licenciados não condiz com à realidade da cidade, onde foram identificados 130 empreendimentos. Constatou-se que 33 postos, ou 25\%, atendem as licenças necessárias e 97 postos, ou 75\%, apresentam alguma pendência, mostrando a necessidade de maior atenção com o rito de licenciamento ambiental, bem como a necessidade de regularização dos empreendimentos com alguma pendência no licenciamento, para haver o adequado controle gerencial sobre tal atividade. Haja vista que se trata de atividade potencial causadora de dano ambiental, frequentemente está situada dentro do ambiente urbano e em condições de águas 
subterrâneas superficiais podem comprometer de forma significativa a qualidade do solo e das águas subterrâneas, com risco a saúde humana.

Palavras-chave: Licenciamento ambiental; Postos de revenda de combustíveis; Riscos de contaminação.

\begin{abstract}
The environmental licensing process is a guarantee of a safe environment for polluting activities. The present work analyzed Belém-PA environmental license files for the gas station segment in association with urban land use and the shallow free aquifer, these factors can compromise environmental quality and risks to the public health. For this purpose, there was carried out a bibliographic research, as well as a survey of information in databases of the municipal, state, federal registry and fire department. Besides, it was concluded that the number of licensed gas stations does not match the reality, where 130 projects were identified. It was found that 33 gas stations, or $25 \%$, meet the necessary licenses and 97 gas stations, or $75 \%$, have some pending issues, showing the need for greater attention to the environmental licensing process, as well as the need to regularize the enterprises with some pending in licensing, to have adequate management control over such activity. Bearing in mind that this is a potential activity that causes environmental damage, it is often located within the urban areas and under conditions of shallow groundwater can compromise the quality of soil and groundwater, with risk to human health.
\end{abstract}

Keywords: Environmental licensing; Gas stations; Contamination risk.

\title{
Resumen
}

Las actividades contaminantes deben pasar por el proceso de licencia ambiental como garantía de un adecuado funcionamiento ambiental. El presente trabajo analizó el registro de licencias en el segmento de estaciones de servicios de la ciudad Belém-PA, relacionadas con la ocupación urbana y las cargas muy superficiales del acuífero libre, factores que pueden comprometer la calidad ambiental y traer riesgos a la salud pública. Para ello, se realizó una investigación bibliográfica, así como un levantamiento de información en bases de datos del registro municipal, estatal, federal y de bomberos. Además, se concluye que el número de estaciones de servicios con licencia no coincide con la realidad, donde se identificaron 130 estaciones. Se encontró que, de 33 estaciones de servicios, 25\%, cumplen con las licencias necesarias y 97 estaciones, es decir, 75\%, tienen algunos asuntos pendientes, evidenciando la necesidad de una mayor atención con el proceso de licenciamiento ambiental, así como la 
necesidad de regularizar las estaciones de servicios con alguna notificación de falta de licenciamiento, a fin de tener un adecuado control de gestión sobre dicha actividad. Teniendo en cuenta que se trata de una actividad que causa potencial daño ambiental, que a menudo se ubica dentro del entorno urbano y que las condiciones de agua subterránea cerca de la superficie del suelo pueden comprometer significativamente la calidad del suelo y las aguas subterráneas, con riesgo para la salud humana.

Palabras clave: Licencia ambiental; Estaciones de servicio; Riesgo a la contaminación.

\section{Introdução}

O aumento populacional e o crescimento da atividade industrial ajudaram a agravar a qualidade ambiental, principalmente em relação à preservação do meio ambiente e dos recursos hídricos superficiais e subterrâneos.

No Brasil, em meados da década de 1970, ocorreu o desenvolvimento econômico e industrial, sem os devidos cuidados com o meio ambiente, principalmente pela ausência de legislação e controle específicos. Para atender essa demanda foram implantados diversos polos petroquímicos e aumentar as redes de distribuição e revenda (Mariano, 2006).

De acordo com a Agência Nacional de Petróleo (2019), “o Brasil apresentou no ano de 2018, 40.021 postos revendedores de combustíveis derivados de petróleo em operação, compreendendo 7,2\% na Região Norte do País". Ressalta-se que as atividades associadas ao refinamento de petróleo e seus derivados são a causa de possíveis e significativas contaminações de águas subterrâneas e solos.

O Estado de São Paulo, o mais industrializado e desenvolvido economicamente do país, passou dar atenção ao gerenciamento das áreas contaminadas, o qual iniciou o cadastramento e levantamento dessas áreas a partir de 2002 com a Companha Ambiental do Estado de São Paulo (CETESB). Dentre as atividades cadastradas que mais contribuíram com a contaminação do solo e das águas subterrâneas constatou-se que os postos de combustíveis representam 74\% do total de registros (CETESB, 2014 apud Lima et al., 2017), vale ressaltar que a atividade postos de combustíveis foi a prioritária no início do cadastro por ser a mais ampla.

A contaminação pode ocorrer por meio do vazamento de combustível dos tanques de armazenamento, problemas estruturais nos tanques do sistema de armazenamento subterrâneo, instalação inadequada desses equipamentos e falta de manutenção. No solo, esses combustíveis se dispersam de maneiras distintas, os quais dependem das características físicas 
do solo, propriedades do composto e ao atingir o aquífero livre se forma um resíduo sobrenadante, o qual movimenta-se horizontalmente contaminando o solo a longo prazo (Carneiro et. al., 2020).

Além disso, a contaminação do solo e da água subterrânea contribui com diversos problemas de saúde pública, pois, devido à grande urbanização e aumento de veículos automotores, os quais utilizam gasolina, diesel e etanol como combustível, nas cidades tornou-se necessária a existência de postos de revenda de combustíveis ao longo do centro urbano e nas vias de interligação.

No caso da gasolina, os hidrocarbonetos monoaromáticos (BTEX) são constituintes mais solúveis e móveis, principalmente pela cossolvência do etanol adicionado, sendo os primeiros a atingir a zona saturada. Esse componente em grande exposição aos seres vivos, pode causar leucopenia, câncer e prejudicar o sistema nervoso central (Penner, 2000).

Em razão disso, esta atividade comercial é classificada, pela Associação Brasileira de Normas Técnicas (ABNT) como Posto de Serviço e pela Agência Nacional de Petróleo (ANP) por meio da Portaria $\mathrm{n}^{\circ} 41$ de 05/11/2013 (ANA, 2013), como Posto Revendedor, representa um "empreendimento potencialmente ou parcialmente poluidor", como menciona a Resolução $n^{\circ} 273$ de 29/01/2000 do Conselho Nacional do Meio Ambiente (CONAMA, 2000).

Assim, para controlar e prevenir a potencial poluição gerada pela atividade comercial de revenda de combustíveis, é necessário que cada Posto Revenda de Combustível (PRC) passe por processo de licenciamento ambiental que possui diversas etapas, as quais são Licença Prévia, Licença de Instalação e Licença de Operação (Silva \& Souza, 2020). Pelo exposto é importante que os postos revendedores de combustíveis (PRCs) estejam devidamente cadastrados, licenciados e sejam fiscalizados, para que haja um controle de quantidade e qualidade da atividade e do meio no qual ele está instalado.

Em Belém, essas atividades comerciais de revenda de combustíveis automotivos são licenciadas pelas secretarias de meio ambiente do estado e municipal de acordo com o volume a ser comercializado, ou seja, pela Secretaria de Municipal de Meio Ambiente (SEMMA) e Secretaria de Estado de Meio Ambiente e Sustentabilidade (SEMAS). O licenciamento ambiental para PRCs se instalarem e operarem no estado, demanda um grande quantitativo de análise de estudos e projetos, requerendo competência e agilidade para atender todos os requerentes.

No Estado do Pará, o licenciamento ambiental dessa atividade é de responsabilidade da SEMAS, a qual segue o seguinte fluxo Gerência de Projeto de Comércio, Serviços e 
Resíduos (GECOS), Coordenadoria de Indústria, Comércio, Serviços e Resíduos (CIND) e Diretoria de Licenciamento Ambiental (DLA). Para ser solicitada a licença ambiental no estado, o futuro PRC deve possuir volume de tancagem superior ou igual à 150 metros cúbicos $\left(\mathrm{m}^{3}\right)$, conforme anexo da Resolução n 117 de 25/11/2014 do Conselho Estadual de Meio Ambiente (COEMA, 2014), e seguir as exigências estabelecidas na Instrução Normativa $\mathrm{n}^{\circ} 11$, de 12 de setembro de 2011 (SEMAS, 2011), para cada fase de licenciamento, ou seja, Licença Prévia (LP), Licença de Instalação (LI) e Licença de Operação (LO).

Além disso, na Instrução Normativa n 11 de 12/09/2011 da Secretaria de Estado de Meio Ambiente e Sustentabilidade (SEMAS, 2011), no Art. $5^{\circ}$, solicita no requerimento de LP, LI e LO, assim como na renovação, o empreendimento deve apresentar as informações necessárias com base na Resolução CONAMA no 273/2000 (CONAMA, 2000) e normas técnicas específicas à atividade comercial.

Em contrapartida, na capital do Estado do Pará, no Município de Belém o licenciamento ambiental dessa atividade é de responsabilidade da Secretaria Municipal de Meio Ambiente (SEMMA), a qual segue o seguinte fluxo Departamento de Controle Ambiental (DCA) e Divisão de Cadastro e Licenciamento (DCL). Semelhantemente à secretaria estadual, a SEMMA possui Instrução normativa ${ }^{\circ}$ 001, de 31 de janeiro de 2011 (SEMMA, 2011), a qual dispõe os procedimentos de licenciamento de PRCs em Belém compreendendo todas as fases. Ademais, para que seja requerida a licença ambiental do empreendimento na secretaria, o PRC deve possuir volume de tancagem igual ou inferior à 150 metros cúbicos $\left(\mathrm{m}^{3}\right)$, conforme anexo da Resolução $\mathrm{n}^{\circ} 120$ de 28/10/2015 do Conselho Estadual de Meio Ambiente (COEMA, 2015).

Sabe-se que a principal configuração de um PRC, em relação à proteção do meio ambiente, está relacionada como é armazenado e comercializado os combustíveis. Isso se dá devido ao grande potencial de poluição desses combustíveis, o qual necessita de proteção constante, a fim de preservar os recursos naturais diretamente relacionados ao armazenamento. Sendo assim, ao ser licenciado pela primeira vez, os PRCs deverão atender os itens dos termos de referência requeridos pelos órgãos ambientais e, consequentemente, estará atendendo a vários itens preconizados em um sistema de gestão ambiental.

Entretanto, apesar dessa atividade ser considerada potencialmente ou parcialmente poluidora e ser necessário licenciamento ambiental, o quantitativo de postos licenciados no município de Belém não retrata a realidade da cidade. Desse modo, objetiva-se nesta pesquisa espacializar e comparar os diversos cadastros de postos revendedores de combustíveis no 
município de Belém-PA e discutir a vulnerabilidade a contaminação do solo e da água subterrânea, enfatizando a ocupação urbana e ao nível do aquífero livre.

\section{Metodologia}

A metodologia utilizada neste trabalho é de estudo de caso que segundo o Pereira A.S. et al. (2018) se trata de uma análise e descrição mais completa de algum caso específico que possa apresentar especificidades os quais o tornem importante. Além disso, a pesquisa possui natureza quantitativa, a fim de alcançar os objetivos propostos. Diante disso, as etapas serão descritas a seguir de acordo com a ordem de coleta de dados do estudo.

\section{1 Área de estudo}

A cidade de Belém, conforme representada a sua localização na Figura 1, possui $1.059,466 \mathrm{~km}^{2}$ de área e população estimada de 1.492.745 habitantes (IBGE, 2019).

Figura 1. Localização do Município de Belém.

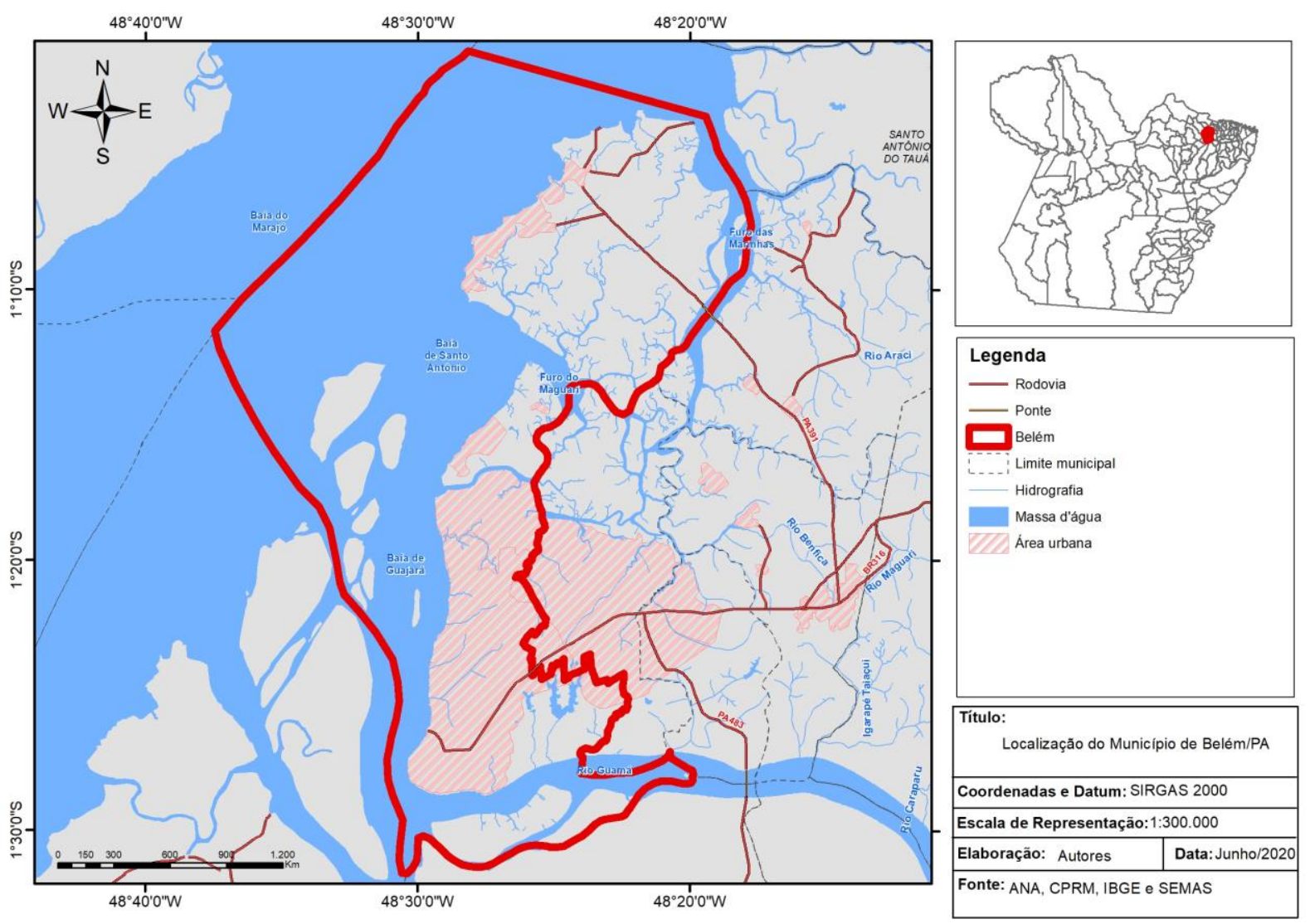

Fonte: Autores. 
De acordo com o Anuário Estatístico de Belém (ANB) (PMB, 2011), os solos do município possuem as mesmas características dos solos da Região Bragantina, as quais são: latossolo amarelo, distrófico, textura média, concrecionários lateríticos indiscriminados, textura indiscriminada; gleieutrófico e distrófico, solos aluviais eutróficos, texturas indiscriminadas.

Além disso, é constituído por restos da formação Barreiras e terrenos do quaternário subatual e do recente. Assim, reflete na litologia, logo, suas formas de relevo caracterizam-se pelos baixos platôs e planícies litorâneas. Quanto a hidrografia, segundo o ANB, os principais acidentes geográficos do município são: as Baías do Marajó, ao norte e do Guajará, a oeste. Sendo a última a que deságua o rio Guamá que em conjunto, contribui para a conformação peninsular do município. Na Baía do Guajará deságuam os Igarapés: Bacuri, Val-de-Cães, Una e o furo do Maguari que separa a ilha de Caratateua (Outeiro) do continente.

\subsection{Levantamentos bibliográficos e de informações}

O método de levantamento bibliográfico foi fundamentado na pesquisa e consulta a bancos de dados secundários, ou seja, livros, periódicos e dados de instituições competentes no âmbito do licenciamento, regulamentação e fiscalização dos postos revendedores de combustíveis, entre as quais se destacam a Secretaria Municipal de Meio Ambiente do município de Belém (SEMMA), Secretaria de Estado de Meio Ambiente e Sustentabilidade (SEMAS), Comando de Bombeiros Militar do Pará (CBMPA) e Agência Nacional de Petróleo (ANP).

Além disso, a obtenção de alguns dados e arquivos shapefiles foi realizada em consulta aos Estudos Hidrogeológicos para a Gestão das Águas Subterrâneas da Região de Belém/PA, gerenciado pela Agência Nacional de Águas (ANA), juntamente com outros órgãos e profissionais.

\subsection{Junção dos cadastros dos postos cadastrados}

A junção dos cadastros e licenças relativas aos postos de combustíveis, se deu por meio a dados cadastrais disponibilizados pelos órgãos licenciadores SEMAS e SEMMA e acesso ao banco de dados virtual CBMPA e ANP, os quais foram incluídos em um banco de dados geral. 
Research, Society and Development, v. 9, n. 10, e6529109100, 2020

(CC BY 4.0) | ISSN 2525-3409 | DOI: http://dx.doi.org/10.33448/rsd-v9i10.9100

Essa etapa tem a finalidade de verificar a semelhança entre cadastros, isto é, se um posto está elencado em esfera federal que diz respeito ao cadastramento na Agência Nacional de Petróleo, gás natural e biocombustíveis e esfera local que corresponde ao alvará de funcionamento dos bombeiros e licenciamento ambiental das secretarias (estadual ou municipal).

\subsection{Avaliações crítica da quantidade de postos cadastrados}

Detendo das informações contidas nos diferentes bancos de dados e a junção entre eles, nem sempre têm correspondência entre si, gerando divergências com a realidade da cidade. Logo, possibilitou a identificação do quantitativo de postos que não estão licenciados. Adicionalmente quando houve dúvida quanto a existência e localização de um posto, utilizouse a ferramenta Google Street View para conferir o posicionamento.

\subsection{Consulta ao Sindicato dos postos de combustíveis}

No dia 03 de março de 2020 foi realizado o contato, por telefone, com a presidente do sindicato de postos de combustíveis do Pará (SINDICOMBUSTÍVEIS-PA), sendo negado qualquer fornecimento de informações. Foi sugerido unicamente que as informações fossem obtidas junto à ANP.

\subsection{Espacialização dos dados}

Todos os postos cadastrados na etapa de Levantamento Bibliográfico e de Informações foram organizados na forma de um banco de dados no software ArcGis, versão 10.5, apto a permitir a consulta das informações e a geração de novos mapas e atualização de informações.

\subsection{Critérios para avaliação da vulnerabilidade}

\section{Adensamento urbano}

A quantidade de postos de combustíveis é maior nos centros urbanos, dessa maneira, é importante ressaltar que edificações próximas à essas atividades estão mais vulneráveis a contaminação dos seus poços de abastecimento de água, sejam eles: público ou individual. 


\section{Profundidade do aquífero livre}

O combustível, principal produto nos referidos postos, pode ser altamente tóxico e prejudicial à saúde, caso não seja, manuseado, armazenado e transportado de forma correta. Assim, quanto mais próxima da superfície do solo for a zona saturada, maior o risco de contaminação do aquífero livre, caso haja vazamentos nos tanques subterrâneos ou em qualquer sistema de líquidos oleosos ou inflamáveis.

\section{Resultados e Discussão}

\subsection{Base de dados}

Os dados dos cadastros e das licenças nos órgãos responsáveis, a qual se utilizou apenas os vigentes, ou seja, estão todos dentro da validade do título foram organizados e tabulados em planilha eletrônica. Assim, o quantitativo referente a cada fonte de consulta está arrolado na Tabela 1.

Além disso, foi possível identificar no sítio da ANP mais informações acerca das autorizações dos postos em Belém. Assim, sabe-se que há 114 autorizações revogadas, isso se dá quando a atividade está sendo exercida em desacordo com a legislação vigente; 19 autorizações canceladas, ou seja, por decretação de falência, por requerimento do revendedor de encerramento da atividade ou constar situação cancelada do Cadastro Nacional de Pessoa Jurídica (CNPJ), Inscrição Estadual (IN) ou Alvará de funcionamento e 3 autorizações de desistentes. Ressalta-se que a consulta ao sítio da ANP remete a março de 2020.

Tabela 1. Quantitativo dos cadastros e licenças obtidos nos órgãos responsáveis.

\begin{tabular}{|c|c|c|}
\hline Órgão & Quantidade & $\%$ \\
\hline ANP & 100 & 38 \\
\hline CBMPA & 109 & 41 \\
\hline SEMMA & 37 & 14 \\
\hline SEMAS & 19 & 7 \\
\hline Total & 265 & 100 \\
\hline
\end{tabular}

Fonte: Autores. 
Na Tabela 1, são especificados o quantitativo dos cadastros obtidos, sendo assim, é importante identificar que os cadastros do CBMPA são referentes ao alvará de funcionamento desses estabelecimentos comerciais. Em relação as licenças ambientais da SEMMA, as informações foram disponibilizadas com o endereço, volume de tancagem e validade da licença. Por fim, as licenças da SEMAS obteve-se informações do tipo de posto, volume de tancagem, validade do título e quantos tanques existem no empreendimento.

De posse dessas informações, inicialmente utilizou-se o software Google Earth PRO para identificar as coordenadas de localização por meio do endereço dos cadastros e licenças. Ressalta-se que em muitas informações não foram disponibilizados e/ou definido um DATUM que está sendo inserido no ato do licenciamento. Assim, houveram diversos endereços incompletos e foi necessário consultar o CNPJ do empreendimento para complementação, sendo que a coordenada indicada e utilizada foi exatamente onde o endereço indicou.

Assim, foi localizado no mesmo lugar PRCs que possuíam CNPJ iguais e ativos, com mesmo endereço e razão social divergente. Identificou-se também, PRCs com CNPJ em situação baixada, isto é, o funcionamento do estabelecimento não foi constatado, mas há licenças ambientais vigentes para o ponto em questão que recai sobre um shopping center. Por outro lado, em coordenadas geográficas da LO divergiram de alguns pontos em que os endereços indicaram.

Houve problemas de identificação da coordenada geográfica em alguns cadastros que o endereço não era localizado ou possuíam características que poderiam nem existir. Sendo assim, foi necessário identificar empreendimentos que possuíam endereço próximo para encontrar manualmente, em algumas situações foram possíveis encontrar e em outras não existia configuração de PRCs aparentemente, situação que pode estar associada evasão contábil e fiscal.

Em outras tentativas, o endereço recaiu sobre ruas afastadas e em terrenos que não apresentavam PRCs. Em relação aos postos flutuantes, algumas coordenadas geográficas que estavam presentes nas licenças não correspondiam ao ponto de localização do posto, mas foi com algumas orientações que indicavam ser próximos à margem da Baía do Guajará que se inferiu a possível posição.

Por fim, foram identificados poucos registros de postos de abastecimento de transportes rodoviários (ônibus) e transportadoras e haviam endereços nos cadastros os quais não possuíam número e não havia como identificar pelo CNPJ, pois apresentavam as mesmas informações, desse modo, marcou-se ponto avulso no mapa. 


\section{Espacialização dos cadastros e licenças}

Após a identificação das coordenadas de localização de cada posto foi possível elaborar o mapa de localização dos postos de cada banco de dados, o qual está ilustrado na Figura 2.

Ficou evidente a diferença do quantitativo de postos cadastrados na cidade de Belém quando visualizado espacialmente, sabe-se que o ideal é que houvesse o mesmo número de postos entre os órgãos. Entretanto, não foi o verificado, e infelizmente não é retratado da realidade da cidade, não há o número total exato de PRCs, já que houve divergência entre os cadastros.

Pelo exposto na Figura 2, infere-se que existem postos em atividade que não possuem licença ambiental para operação, ou seja, estão em desconformidade com às legislações vigentes e contribuindo diretamente e indiretamente com a degradação e poluição ambiental, fora uma provável evasão fiscal. Haja vista que a licença ambiental é imprescindível para regular e definir critérios de harmonia entre a atividade de comercialização de revenda de combustíveis e o meio físico na qual ela está inserida.

Figura 2. Espacialização geral do banco de dados de todos os órgãos.
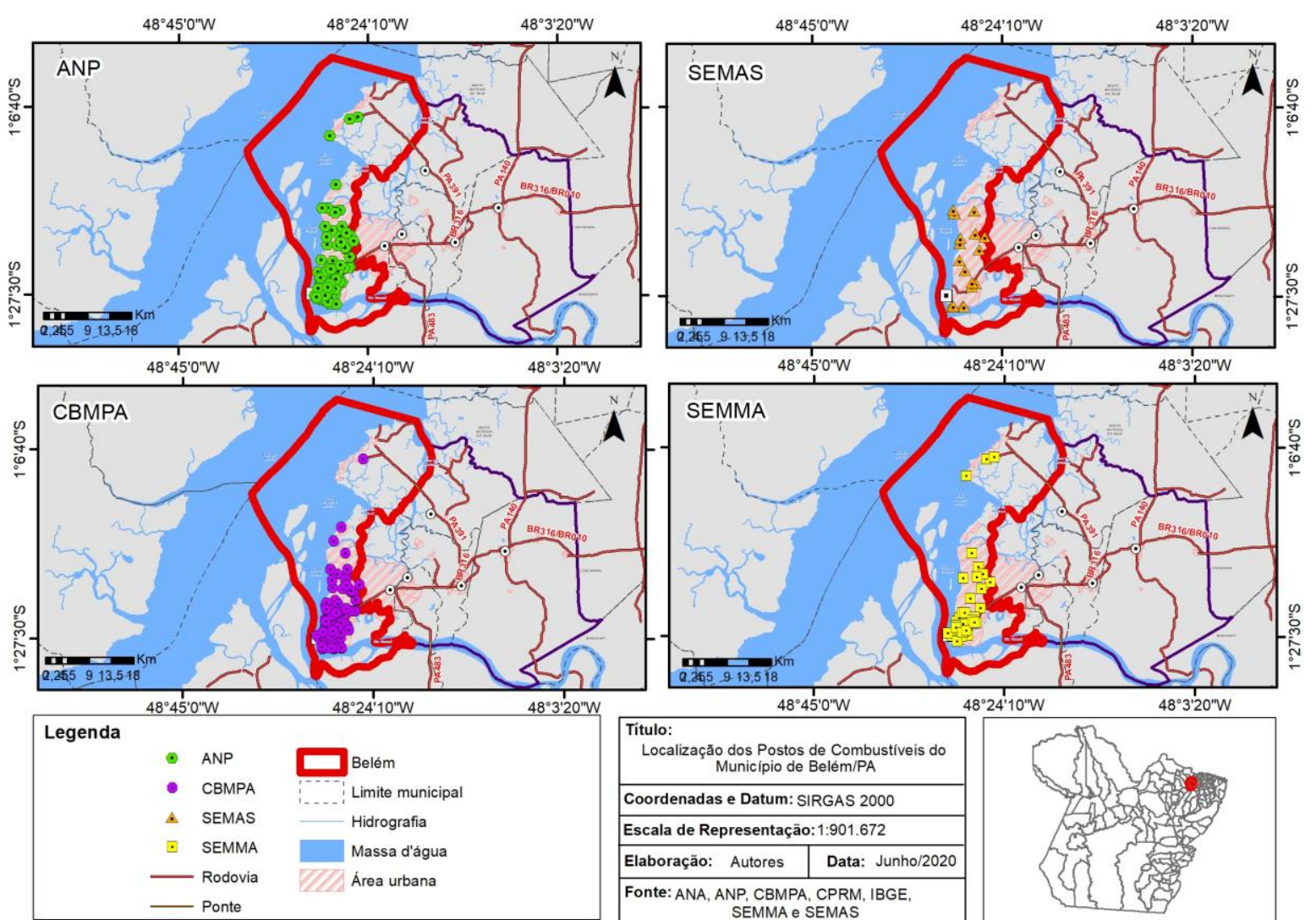

\begin{tabular}{|c|c|c|}
\hline 320 & \multicolumn{2}{|c|}{$48^{\circ} 45^{\prime} \mathrm{O}^{\prime \prime} \mathrm{W}$} \\
\hline & \multicolumn{2}{|c|}{$\begin{array}{l}\text { Título: } \\
\text { Localização dos Postos de Combustiveis do } \\
\text { Município de Belém/PA }\end{array}$} \\
\hline & \multicolumn{2}{|c|}{ Coordenadas e Datum: SIRGAS 2000} \\
\hline & \multicolumn{2}{|c|}{ Escala de Representaçäo: 1:901.672 } \\
\hline & Elaboração: Autores & Data: Junho/2020 \\
\hline & $\begin{array}{l}\text { A, ANP, CE } \\
\text { SEMN }\end{array}$ & $\begin{array}{l}\text { CPRM, IBG } \\
\text { EMAS }\end{array}$ \\
\hline
\end{tabular}

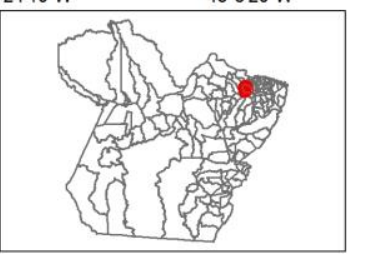

Fonte: Autores. 


\section{Junção dos dados cadastrais e de licenças}

Conforme exposto anteriormente, na espacialização individual de cada banco de dados, demonstrou-se que há pontos que não aparecem nos outros. A fim de verificar semelhanças e identificar pontos existentes nos cadastros, agruparam-se todas as informações e assim tornou-se possível a identificação, como ilustrado na Figura 3.

A Figura 3 possibilita identificar os pontos que estão "em acordo", ou seja, atendem as licenças ambientais, enquanto que "em desacordo" apresentam alguma pendência nas licenças. Posteriormente, foi possível identificar as modalidades existentes, conforme disposto na Resolução ANP no 41/2013 (ANP, 2013), que descreve quais existem e podem exercer a atividade varejista de revenda de combustíveis automotivos. Assim, constatou-se as seguintes modalidades, de acordo com a Tabela 2, vale ressaltar que abastecimento próprio diz respeito à um posto que possui licença para revenda e abastecimento próprio, por isso contabilizou-se duas vezes.

Figura 3. Junção dos dados cadastrais e de licenças.

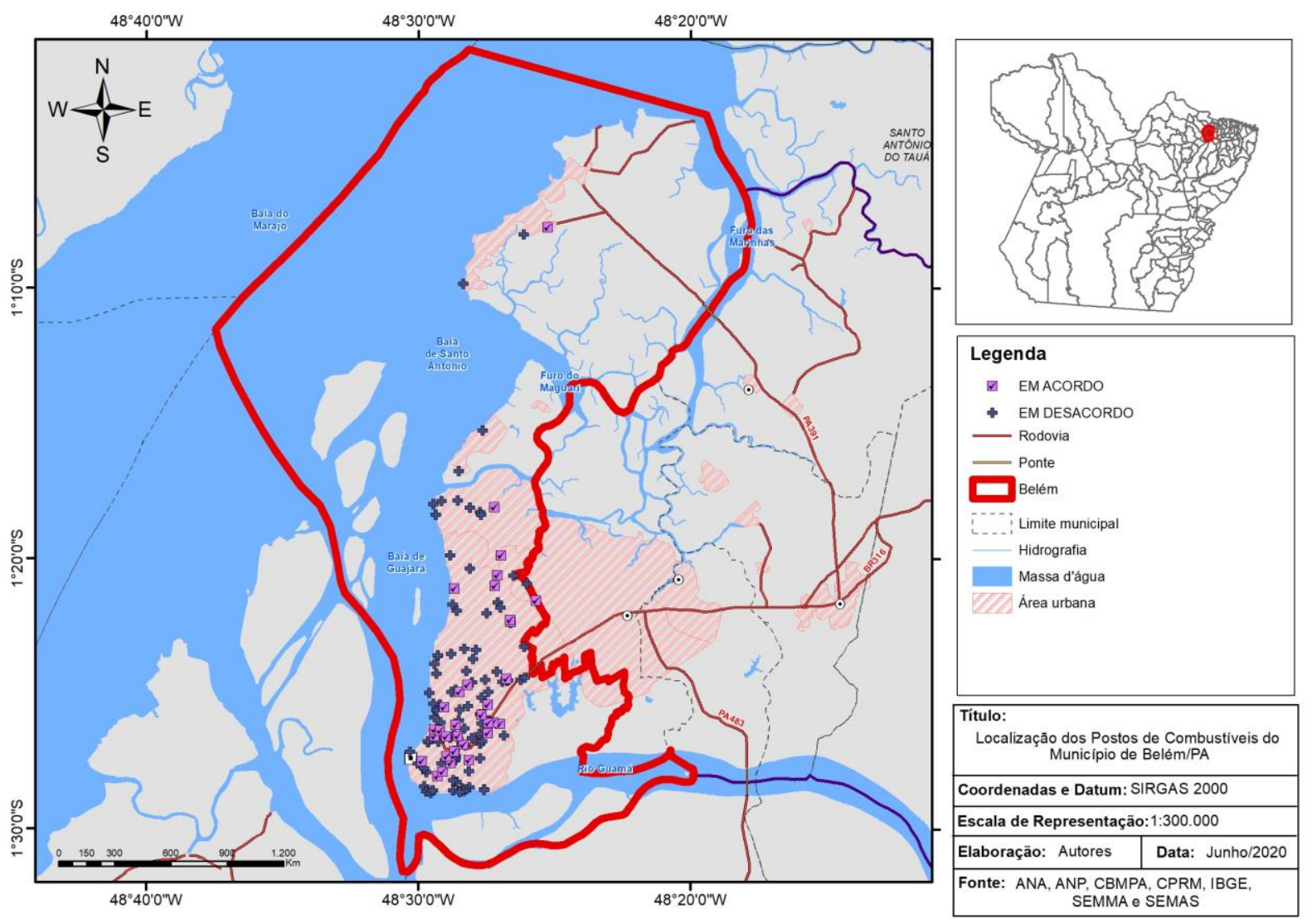

Fonte: Autores. 
Research, Society and Development, v. 9, n. 10, e6529109100, 2020

(CC BY 4.0) | ISSN 2525-3409 | DOI: http://dx.doi.org/10.33448/rsd-v9i10.9100

Tabela 2. Quantitativo dos cadastros e licenças obtidos nos órgãos responsáveis.

\begin{tabular}{|c|c|c|}
\hline Modalidades & Quantidade & $\%$ \\
\hline Abastecimento próprio & 1 & 1 \\
\hline Posto Flutuante & 7 & 5 \\
\hline Posto Revendedor & 122 & 94 \\
\hline Total & 130 & 100 \\
\hline
\end{tabular}

Fonte: Autores.

$\mathrm{Na}$ Tabela 2, é possível identificar que há uma modalidade de "abastecimento próprio", o qual diz respeito à um posto que possui licença para revenda e abastecimento próprio, por isso contabilizou-se duas vezes. Além disso, esse posto que apresentou duas modalidades, tem como atividade no CNPJ de pesca de peixes em água doce, também não há indicativo da presença de PRC no endereço e lugar identificado. Ademais, possibilitou dividir em categorias essas informações obtidas na espacialização geral, isto é, haviam convergências e divergências entre eles. Assim, na Tabela 3 está listado as categorias e o quantitativo de PRCs enquadrados.

Já na Tabela 3, foram listadas as categorização das licenças e cadastros, assim, é importante ressaltar que os PRCs que não apresentam licença ambiental podem estar sem licença ou não renovaram a licença há muitos anos, já que, para solicitar autorização da ANP, o PRC deve apresentar no ato da solicitação o alvará de funcionamento expedido pelo CBMPA ou prefeitura e a licença de operação expedida por órgão ambiental competente. A categoria "com vários cadastros em apenas um ponto", diz respeito a presença de duas ou mais licenças em um mesmo ponto com razão social diferente e CNPJ diferente. Para totalizar os 130 pontos agrupados, caracterizou-se os cadastros e licenças, conforme Tabela 4.

Tabela 3. Quantitativo dos cadastros e licenças obtidos nos órgãos responsáveis.

\begin{tabular}{|c|c|c|}
\hline Categoria & Quantidade & $\%$ \\
\hline Sem licença ambiental / cadastro na ANP e no CBMPA & 46 & 50 \\
\hline Com licença ambiental / cadastros na ANP e no CBMPA & 30 & 32 \\
\hline $\begin{array}{c}\text { Licença ambiental / sem cadastro na ANP / cadastro no } \\
\text { CBMPA }\end{array}$ & 5 & 5 \\
\hline $\begin{array}{c}\text { Licença ambiental / sem cadastro no CBMPA / cadastro na } \\
\text { ANP }\end{array}$ & 5 & 5 \\
\hline Com vários cadastros em apenas um ponto & 7 & 8 \\
\hline Total & 93 & 100 \\
\hline
\end{tabular}

Fonte: Autores. 
Research, Society and Development, v. 9, n. 10, e6529109100, 2020

(CC BY 4.0) | ISSN 2525-3409 | DOI: http://dx.doi.org/10.33448/rsd-v9i10.9100

Tabela 4. Quantitativo dos cadastros e licenças obtidos nos órgãos responsáveis.

\begin{tabular}{|c|c|c|}
\hline Órgão & Quantidade & $\%$ \\
\hline EM ACORDO & 33 & 25 \\
\hline EM DESACORDO & 97 & 75 \\
\hline Total & 130 & 100 \\
\hline
\end{tabular}

Fonte: Autores.

Na Tabela 4 é possível verificar que o quantitativo de $75 \%$ dos cadastros corresponde aos PRCs que estão com algum cadastro ou licença ambiental faltante ou não identificado, caracterizando-o como em desacordo com a legislação, enquanto que $25 \%$ estão em acordo, possuindo cadastros e licenças ambientais. Isso pode ser indicativo de discordâncias e falhas no controle de licenças ambientais, pode ser falha nos cadastros, isto é, endereços incorretos, principalmente.

\subsection{Critérios de vulnerabilidade}

Para verificar a vulnerabilidade a contaminação do solo e das águas subterrâneas foram definidos dois critérios: uso e ocupação do solo, especificamente adensamento urbano, que diz respeito a área edificada e profundidade do aquífero livre, onde pode ser encontrada a água infiltrada no solo e é caracterizada como a zona saturada.

\section{Adensamento urbano}

Sabe-se que existem diferentes tipos de uso e ocupação do solo e eles influenciam em escalas maiores e menores nas condições do meio, principalmente os resultantes de atividades antrópicas. A influência do uso do solo é direta nos recursos hídricos superficiais e subterrâneos, principalmente em relação à qualidade da água.

Com o uso e ocupação do solo de Belém e os pontos de localização dos PRCs foi possível representar onde há maior aglomeração de postos e sua relação com as características do solo, ilustrado na Figura 4. 
Figura 4. Uso e ocupação do solo do Município de Belém.

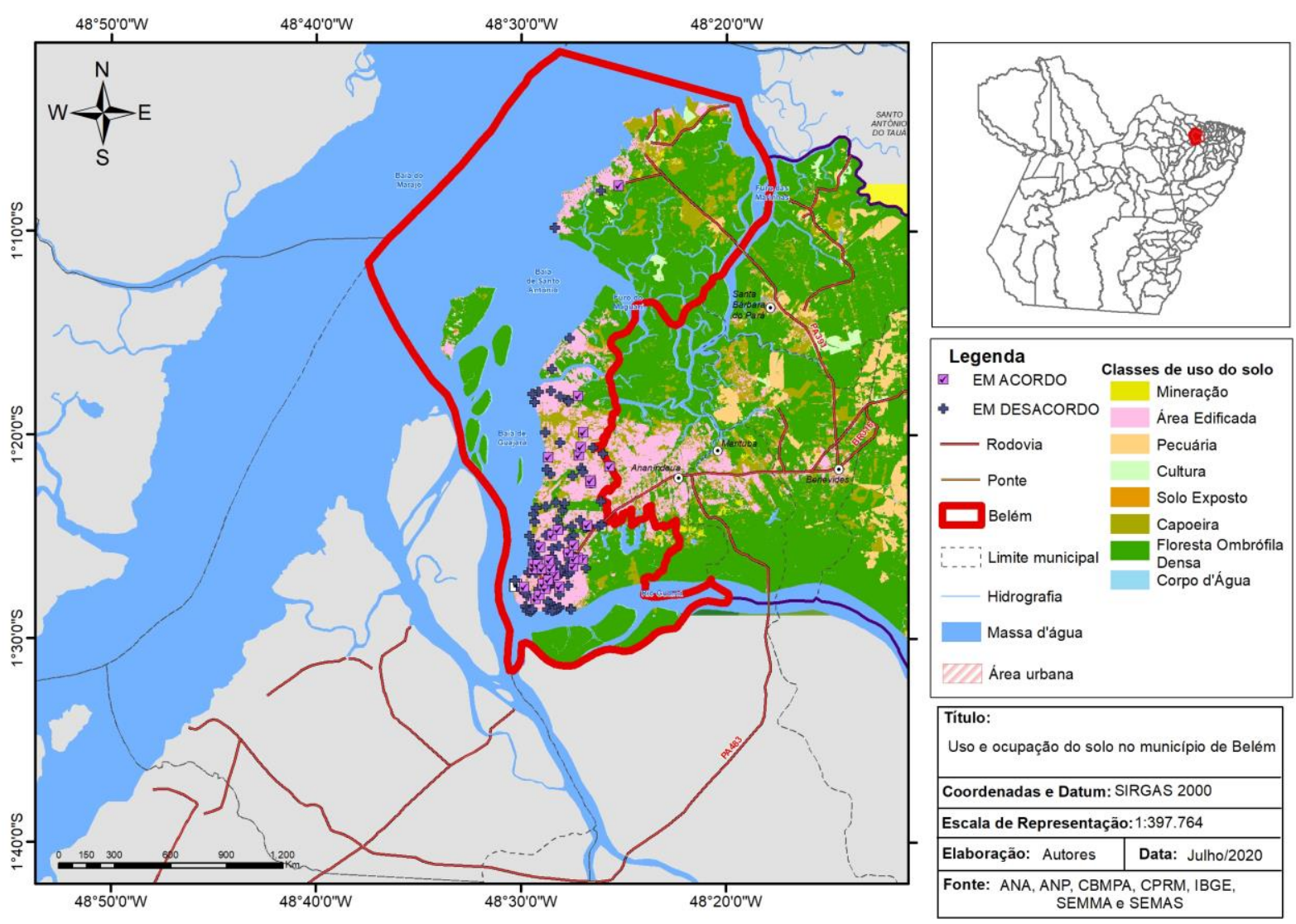

Fonte: Autores.

Na Figura 4, ilustrou-se todos os pontos que estão "em acordo" e "em desacordo", conforme explicado anteriormente, seguido das classes presentes de uso do solo no município obtido no estudo hidrogeológico para a Gestão das Águas Subterrâneas da Região de Belém.

Sendo assim, a cidade de Belém possui grande adensamento urbano e devido à essa ocupação urbana, especificamente as águas subterrâneas estão expostas a diversos tipos de contaminantes. Sabe-se que entre esses contaminantes estão os combustíveis, provenientes de postos revendedores, seja por vazamentos em tanques e tubulações, seja por derramamento (Souza \& Luiz, 2017).

As áreas edificadas na cidade correspondem a $12,43 \%$ ou $131,78 \mathrm{~km}^{2}$ da sua área total de 1.059,5 km² (ANA, 2018a). Essas áreas urbanizadas são caracterizadas, grande parte, por ocupações irregulares e precárias, ou seja, com baixo índice de atendimento de serviços de saneamento e elevada densidade demográfica.

É importante verificar o adensamento urbano nas proximidades dos PRCs, pois, no ato do licenciamento ambiental é necessário identificar a classe do posto de serviço, conforme a NBR 13.786/2019. A partir disso, é realizada a análise do ambiente em torno, a NBR dista em 
100 metros a partir do seu perímetro e é utilizado como parâmetro para a SEMMA. Enquanto que para a SEMAS, define-se uma análise e caracterização do ambiente em um raio de 200 metros a partir da escolha do local, a fim de verificar a existência de edificações comerciais, residências, habitações multifamiliares com ou sem garagem subterrânea, hospitais, escolas etc.

Além disso, conforme IN 011/2011 da SEMAS, é solicitado que os PRCs possuam distância mínima de 20 metros entre a parede externa do tanque de armazenamento de combustível e o limite da propriedade. Nesse sentido, é definido uma distância mínima de 200 metros do SASC do PRC em relação a outros empreendimentos que operem com armazenamento de petróleo e derivados.

Essas distâncias são pelos órgãos ambientais competentes exigidas e recomendadas por Normas Técnicas, ressalta-se que a conferência dessas distâncias não foi abrangida pelo estudo, entretanto, infere-se que estejam em conformidade em razão da grande parte dos postos de combustíveis do estudo estar licenciados.

No licenciamento ambiental de um PRC é solicitado muitas informações, algumas citadas anteriormente, dentre elas é requerido um estudo da caracterização hidrogeológica da localidade, contendo profundidade do aquífero livre, características de permeabilidade do solo, bom ficar atento com a diferença entre permeabilidade e condutividade hidráulica, entre outras. É fundamental conhecer sobre os poços de captação destinados ao abastecimento público ou alternativo, considerando, primordialmente as possíveis interferências nos corpos d'água superficiais e subterrâneos.

\section{Profundidade do aquífero livre}

Um fator de vulnerabilidade à contaminação das águas subterrâneas é a profundidade da zona saturada, ou seja, onde pode se encontrar água infiltrada no solo que é utilizada, entre outras finalidades, para abastecimento humano. Nesse sentido, foi elaborado um mapa contendo a profundidade do aquífero livre, o qual foi obtido por ensaios de infiltração e monitoramento de poços no estudo hidrogeológico para a Gestão das Águas Subterrâneas da Região de Belém e os postos localizados em Belém, ver Figura 5. 
Figura 5. Profundidade do Aquífero Livre do Município de Belém.

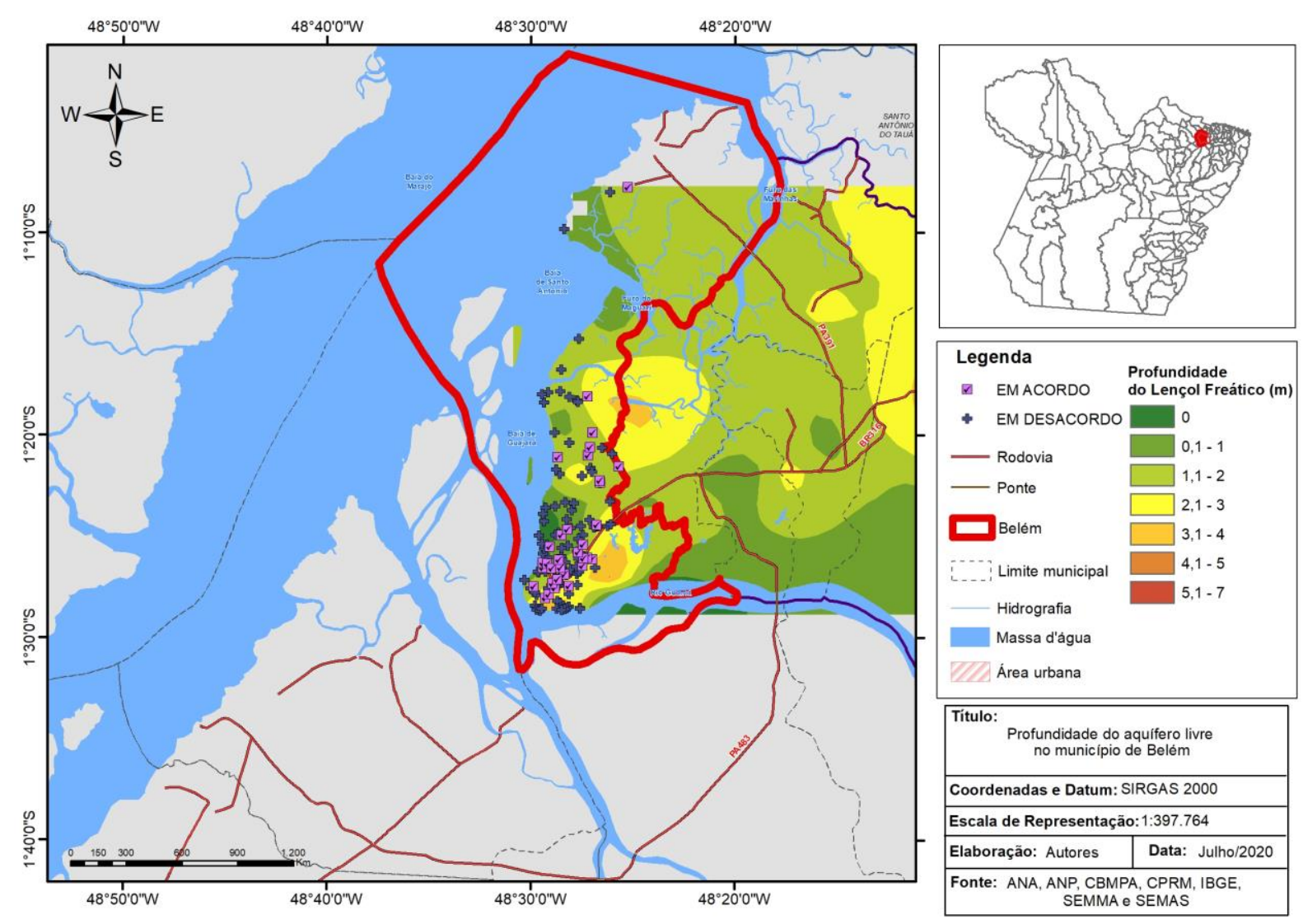

Fonte: Autores.

Nesse cenário, sabe-se que a recarga das águas no subsolo ocorre, geralmente, devido à infiltração da água de chuva em excesso no solo, atividades realizadas neste solo podem ameaçar a qualidade da água subterrânea (Lourencetti et al., 2007). Os aquíferos, em tese, estão protegidos da contaminação, entretanto, podem ocorrer com o descarte de carga contaminante gerada por atividade antrópica, os quais percolam no solo e podem atingir o aquífero livre, bem como aquíferos mais profundos. Alguns contaminantes excedem a capacidade de atenuação das camadas do solo.

As características físicas do subsolo conseguem atenuar diversos poluentes da água e são considerados ativamente eficazes para a eliminação de excretas humanas e de esgoto doméstico. Não obstante, não são todos os perfis e estratos do subsolo que são semelhantemente eficazes na diminuição dos contaminantes. Sendo assim, os aquíferos estão especialmente vulneráveis à contaminação (ANA, 2018a).

A contaminação da água subterrânea ocorre quando a carga contaminante é inadequadamente controlada e em alguns componentes excede a capacidade natural de diminuição nos estratos dos solos (Foster et al., 2013 apud ANA, 2018a). Esse grau de 
atenuação pode variar consideravelmente em relação aos tipos de poluentes, logo é necessário o controle ambiental de quais atividades poluidoras existem e como elas atuam na manutenção e proteção do meio ambiente.

No estudo hidrogeológico para a Gestão das Águas Subterrâneas da Região de Belém (ANA, 2018a), foi identificado o comprometimento qualitativo de quase todos os cursos d'água e os aquíferos mais superficiais. Além disso, foi considerou-se as principais fontes potenciais de poluição das águas subterrâneas os postos de combustíveis, fossas sépticas, cemitérios e lixões (irregulares ou não).

A contaminação das águas, sejam superficiais ou subterrâneas, não eram prioridades de discussão e remedição pela sociedade e órgãos ambientais competentes. Entretanto, com o crescimento urbano, esses recursos hídricos estão sendo potencialmente contaminados em grandes intensidades pelas cargas contaminantes oriundos de atividades e excretas humanas, vazamentos de postos de combustíveis, entre outros (Oliveira et al., 2002).

Em Belém, a população urbana atendida pelo sistema público de abastecimento de água é em torno de 71\%, conforme Ranking do Saneamento do Trata Brasil (2018). Além disso, as principais fontes alternativas aos sistemas públicos de abastecimento utilizadas pela população, são: poços ou nascentes, água da chuva armazenada em cisternas, captações em rios, igarapés, principalmente (IBGE, 2010 apud ANA, 2018b).

Essas informações foram então agrupadas em relação às águas superficiais e subterrâneas, resultando nos percentuais de $98 \%$ e $2 \%$, para fontes de captações alternativas de recursos hídricos subterrâneos e superficiais, respectivamente (ANA, 2018b). Isso evidencia mais a sua importância e, consequentemente, a necessidade de sua preservação.

A cidade de Belém possui chuvas constantes, isto é, apresenta duas estações bem delimitadas: estação chuvosa (dezembro a maio) e estação menos chuvosa (junho a novembro) (Moraes \& Filho, 2018). No estudo realizado pela ANA na região, verificou-se consultando a série histórica de 1983 a 2016 de uma estação da cidade, a precipitação média anual total é de 3.157 milímetros. Assim, como toda água precipitada ao atingir o solo infiltra, quando atinge sua capacidade de infiltração, isto é, satura, há escoamento superficial.

Sabe-se que nas grandes cidades, existem milhares de tanques enterrados, armazenando derivados de hidrocarbonetos em postos de gasolina. Desse modo, é necessário licenciar e controlar ambientalmente essa atividade comercial, a qual é potencialmente poluidora e ameaça a manutenção do meio ambiente e águas subterrâneas. 


\section{Considerações Finais}

Nesse trabalho foi realizado um panorama geral do quantitativo de postos de revenda de combustíveis cadastrados na cidade de Belém-PA e como a atividade pode contribuir para contaminação do solo e da água subterrânea. Desse modo, a partir dos resultados obtidos, identificou-se que existem apenas $25 \%$ dos PRCs estão em acordo com a legislação, enquanto que há $75 \%$ em desacordo, o que pode indicar que estão operando sem nenhum controle ambiental.

A realidade no município é de adensamento urbano, bem como o constante surgimento de atividades de revenda de combustíveis requerem atenção e gestão ambiental, isto é, conhecer, licenciar e, consequentemente, obter o controle efetivo ambiental dessa atividade com grande potencial de contaminação do meio ambiente. Para tanto, é importante fortalecer o acompanhamento dos órgãos ambientais licenciadores desde a licença prévia, de novos empreendimentos, e após a renovação da licença de operação de empreendimentos existentes.

Além disso, é sugestivo que possa ser solicitada a coordenada de localização do posto seja no ato do licenciamento em formato "kmz.", extensão do software Google Earth PRO, e visualização pelo aplicativo Google Street View para constatar a existência do empreendimento, caso ainda ocorra dúvida quanto a localização, pode-se realizar visita in loco. Para acompanhamento dessa atividade, pode-se solicitar a Anotação de Responsabilidade Técnica (ART) do acompanhamento ambiental do empreendimento e o Responsável Legal para que caso seja identificado alguma divergência ou inconformidade com às legislações ambientais, essa pessoa física seja responsável a responder legalmente, como é realizado pela CETESB em São Paulo.

Como citado ao longo do texto, mencionando-se sobre a utilização da água subterrânea como manancial de abastecimento humano, reafirma a necessidade de investigações sistemáticas e de meios e longos prazos. Os resultados podem ser utilizados como alerta, para o gerenciamento dessas áreas e atentar sobre a ineficiente interação entre os órgãos ambientais estaduais e municipais com a ANP, visto que é necessária uma ação conjunta, bem como o fomentar o ensino e a pesquisa nas universidade em parceria com os órgãos ambientais competentes, visando sempre o desenvolvimento sustentável da atividade econômica na região.

Assim, é evidente que o desenvolvimento sustentável exige ações preventivas e ficando evidente a necessidade de transparência referente às informações de licenciamento ambiental e acompanhamento, resultando em um banco de dados sobre o quantitativo real de 
todos os postos existentes em Belém. É imprescindível a proporção de orientações junto aos postos e Sindicato de Postos de Combustíveis do Pará a obrigatoriedade do licenciamento ambiental do Posto Revendedor de Combustíveis, para que se previnam os potenciais danos ambientais oriundos de suas atividades.

Por fim, com o presente trabalho espera-se que outros trabalhos sejam desenvolvidos acerca da temática, assim, podem desenvolvidos pesquisas e coletas em poços de abastecimento de residências próximas de PRCs para verificar se existe interferências qualitativas na água. Além disso, sugere-se mapear e identificar postos de abastecimento de transportes rodoviários (ônibus) e/ou de transportadoras, visto que são passíveis de licença ambiental.

\section{Referências}

Agência Nacional de Águas - ANA. (2018a). Estudos Hidrogeológicos para Gestão das Águas Subterrâneas da Região de Belém/PA.

Agência Nacional de Águas - ANA. (2018b). Estudos Hidrogeológicos para Gestão das Águas Subterrâneas da Região de Belém/PA (Relatório Temático de Urbanização).

Agência Nacional do Petróleo, gás natural e biocombustível. (ANP). 2019. Anuário estatístico brasileiro do petróleo, gás natural e biocombustível 2019. ISSN 1983-5884. Recuperado de http://www.anp.gov.br/publicacoes/anuario-estatistico/5237-anuario-estatistico-2019.

Agência Nacional do Petróleo, gás natural e biocombustível. (ANP). 2013. Resolução $n^{\circ} 41$. Atribuições legais e requisitos básicos. Brasil. 2013. Publicada no DOU, de 6 de novembro de 2013.

Associação Brasileira de Normas Técnicas. (ABNT). 2019. NBR 13786. Armazenamento de líquidos inflamáveis e combustíveis - Seleção dos componentes do combustível (SASC) e sistema de armazenamento subterrâneo de óleo lubrificante usado e contaminado (OLUC). Rio de Janeiro, 2019.

Carneiro, G. C. A., Dias, D. A. F., Fonseca, E. R., Gonçalves, J. A. C. (2020). Contaminação das águas subterrâneas por compostos orgânciso na bacia hidrográfica do rio das Velhas, no 
Research, Society and Development, v. 9, n. 10, e6529109100, 2020

(CC BY 4.0) | ISSN 2525-3409 | DOI: http://dx.doi.org/10.33448/rsd-v9i10.9100

estado de Minas Gerais, Brasil. Research, Society and Development, 9(10), 1-19. http://dx.doi.org/10.33448/rsd-v9i10.8536

Conselho Estadual de Meio Ambiente. (COEMA). Resolução n ${ }^{\circ} 117$. Estabelece alteração da tabela de enquadramento das atividades sujeitas à cobrança de taxas pelo exercício regular do poder de polícia administrativa ambiental. Pará. 2014. Publicada no DOE nº 32.783, de 05 dezembro de 2014, páginas 34-47.

Conselho Estadual de Meio Ambiente. (COEMA). Resolução $n^{\circ} 120$. Dispõe sobre as atividades de impacto ambiental local, de competência dos municípios e dá outras providências. Pará. 2015. Publicada no DOE n 33.003, de 03 novembro de 2015, páginas 31 31.

Conselho Nacional do Meio Ambiente (CONAMA). (2000). Resolução no 273. Estabelece diretrizes para o licenciamento ambiental de postos de combustíveis e serviços e dispõe sobre a prevenção e controle da poluição. Brasil. 2000. Publicada no DOU n5, de 8 de janeiro de 2001, Seção 1, páginas 20-23.

Instituto Brasileiro de Geografia e Estatística. (IBGE). 2019. Panorama da cidade de Belém. Recuperado de https://cidades.ibge.gov.br/brasil/pa/belem/panorama.

Lima, S. D., Oliveira, A. F., Golin, R., Caixeta, D. S., Lima, Z. M., Morais, E. B. (2017). Gerenciamento de áreas contaminadas por postos de combustíveis em Cuiabá, Mato Grosso, Brasil. Ambiente e Água, 12(2), 299-315. https://doi.org/ 10.4136/ambi-agua.1872

Lourencetti, C., Ribeiro, M. L., Pereira, S. Y., Marchi, M. R. R. Contaminação de águas subterrâneas por pesticidas: avaliação preliminar. Química Nova, 30(3), 688-694. http://dx.doi.org/10.1590/S0100-40422007000300031

Mariano, A. P. (2006). Avaliação do Potencial de Biorremediação de Solos e de Águas Subterrâneas Contaminados com Óleo Diesel. [Tese (Doutorado)]. Universidade Estadual Paulista. 
Mariano, A. P. (2006). Avaliação do Potencial de Biorremediação de Solos e de Águas Subterrâneas Contaminados com Óleo Diesel. [Tese (Doutorado)]. Universidade Estadual Paulista.

Moraes, D., Filho, M. (2018). Contribuição das chuvas do período da tarde em Belém e possíveis relações com a normal climatológica. Revista Brasileira de Climatologia, 23(14), 17-32. http://dx.doi.org/10.5380/abclima.v23i0.58364

Oliveira, J. R., Melo, A. F., Pinto, J. A., Souza, A. N. (2002). Controle de vazamentos em postos de combustíveis na Região Metropolitana de Belém e seus aspectos Jurídicos. XII Congresso Brasileiro de Águas Subterrâneas, 1-9.

Penner, G. C. (2000). Estudos Laboratoriais da Contaminação do solo por gasolina com o uso de Detetor de Fotoionização. [Dissertação (Mestrado)]. Universidade de São Paulo.

Pereira, A. S., Shitsuka, D. M., Parreira, F. J., Shitsuka, R. (2018). Metodologia da Pesquisa Científica. Santa Maria: Universidade Federal de Santa Maria - Núcleo de Tecnologia da Educação. Recuperado de https://repositorio.ufsm.br/handle/1/15824

Prefeitura Municipal de Belém (PMB). 2012. Anuário estatístico de Belém: Caracterização do território do município. Recuperado de http://www.belem.pa.gov.br/tra nsparencia/?page_id=1510.

Secretaria de Estado de Meio Ambiente e Sustentabilidade. (SEMAS). (2011). Instrução Normativa $n^{\circ} 11$. Estabelece diretrizes para o licenciamento ambiental de Posto Revendedor PR, Posto de Abastecimento - PA, Instalações de Sistema Retalhista - ISR, Posto Flutuante PF e Serviços no Estado do Pará. Pará. 2011. Publicada no DOE n 31.996, de 12 setembro de 2011, páginas 13-15.

Secretaria Municipal de Meio Ambiente. (SEMMA). (2011). Instrução Normativa $\mathrm{n}^{\circ} 001$. Disciplina o processo de licenciamento ambiental dos postos revendedores de derivados de petróleo e biocombustíveis, localizados no município de Belém, bem como os procedimentos a serem adorados em caso de incidentes e/ou acidentes ambientais e constatação de passivos 
ambientais dos mesmos. Belém. 2011. Publicada no DOM nº 11.786, de 01 fevereiro de 2011, páginas 6-8.

Silva, V. P., Souza, S. K. S. (2020). Caracterização ambiental de posto de revenda de combustíveis sob a ótica de adequação ambienal. Research, Society and Development, 9(7), 1-24. http://dx.doi.org/10.33448/rsd-v9i7.3527

Souza, D. M., Luiz, J. G. (2017). Radar de penetração no solo aplicado a análise ambiental de posto de combustíveis pós-remediação. Águas subterrâneas, 31 (3), 143-153. https://doi.org/10.14295/ras.v31i3.28797

Trata Brasil. 2018. Ranking do Saneamento 2018. Recuperado de http://tratabrasil.org. br/estudos/estudos-itb/itb/ranking-do-saneamento-2018.

Porcentagem de contribuição de cada autor no manuscrito

Cleyanne Kelly Barbosa Souto - 70\%

Giovanni Chaves Penner - 30\% 